\title{
Accident and emergency services for children within Trent region
}

\author{
S Playfor
}

\begin{abstract}
Objectives-To investigate the provision of accident and emergency ( $A \& E$ ) services for children within Trent region, and to compare these with published recommendations.

Methods-A postal questionnaire was sent to all $\mathrm{A} \& \mathrm{E}$ and minor injury units within Trent region providing services for children. Findings were compared with published recommendations including those of the Multidisciplinary Working Party into Accident and Emergency Services for Children.

Results-Thirty six units provided A\&E services for children within Trent: 17 mixed units, 17 minor injury units and two children's units. Within mixed A\&E units complete audio-visual separation from adult patients was provided by six units $(35 \%)$, inpatient paediatric facilities were available at 11 units $(65 \%)$ and a minimum of one registered children's nurse was always on duty in three units (18\%).

Conclusions-Few A\&E units within Trent region currently meet the recommendations of the Multidisciplinary Working Party. The most common shortfall identified was in the provision of registered children's nurses.

(Emerg Med f 2001;18:164-166)
\end{abstract}

Keywords: children; facilities

Children account for approximately one third of all patients seen in accident and emergency (A\&E) departments. ${ }^{1}$ Between three and four million children attend such departments each year and by their fifth birthday $44 \%$ of children will have attended an $\mathrm{A} \& \mathrm{E}$ unit. ${ }^{2}$

The Multidisciplinary Working Party into Accident and Emergency Services for Children published their report in June $1999^{3}$ and their key recommendations are summarised below.

- Audio-visual separation of children from adult patients must be provided.

- Only A\&E departments that are on the same hospital site as inpatient paediatric facilities should accept children.

Care Unit,

Birmingham

Children's Hospital,

Birmingham, UK

Correspondence to: Dr Playfor, c/o PICU, Toronto Sick Children's Hospital, 555 University Avenue, Toronto, Ontario, Canada M5G $1 X$

Accepted for publication 4 September 2000 between A\&E medicine, primary health care and paediatrics.

Trent is one of the eight National Health Service regions in England and includes 11 health authorities and 43 NHS trusts; it has a population of 5.1 million of whom 974000 are under the age of 15 . We have reviewed the provision of A\&E services for children within Trent region and have assessed how well these units meet various service standards including the first three of the Multidisciplinary Working Party recommendations described above.

\section{Methods}

A\&E units that accept children within Trent region were identified by reference to a local handbook, the Trent Directory. ${ }^{4}$ Telephone contact was made with those units to identify a named individual nurse who had a particular responsibility for, or interest in, the care of children.

A seven page questionnaire was constructed by drawing together various published recommendations relating to the provision of children's services, which included the first three recommendations of the Multidisciplinary Working Party described above. The questionnaire was mailed to each unit during September 1998; two follow up letters were sent to non-respondents at six week intervals followed by a final telephone prompt if required.

The questionnaire covered many aspects of A\&E services. Departments were asked to describe their unit and give the number of annual attendances for adults and children, and if they used computerised records. Units were asked about the provision of paediatric inpatient services, audio-visual separation from adults and the minimum number of registered children's nurses working on each shift that children are nursed. We also investigated triage facilities, waiting and consultation areas and the use of paediatric pain assessment tools. Other topics included breast feeding, nappy changing and pushchair storage facilities, safety issues, health information and the use of play specialists.

Resuscitation issues included paediatric resuscitation training, the equipping of resuscitation areas and a checklist of drugs that would ideally be stocked in this area. It is agreed that an appropriate quiet room for parents should be provided in A\&E departments and we therefore asked about the provision of such a room.

It was established whether there was a named $\mathrm{A} \& \mathrm{E}$ doctor and senior nurse responsible for children's issues and if a doctor with paediatric experience worked on each shift. We assessed the use of written guidelines for the 
Table 1 Compliance with key recommendations of the RCPCH Working Party by unit type

\begin{tabular}{|c|c|c|c|}
\hline & $\begin{array}{l}\text { Minor injuries } \\
\text { units (17 units) }\end{array}$ & $\begin{array}{l}\text { Mixed } A \mathcal{E} E \\
\text { units (17 units) }\end{array}$ & $\begin{array}{l}\text { Children's } A \mathcal{E} E \\
\text { units (2 units) }\end{array}$ \\
\hline Audio-visual separation from adults & 6 & 35 & 100 \\
\hline Co-location of inpatient services & 0 & 65 & 100 \\
\hline Provision of registered children's nurses & 6 & 18 & 100 \\
\hline
\end{tabular}

Data shown as percentages.

management of non-accidental injury, cot death, deliberate self harm, pain relief, burns and scalds.

\section{Results}

There were 36 A\&E units within Trent region providing services for children. Seventeen of these were mixed $\mathrm{A} \& \mathrm{E}$ units (47\%), 17 were minor injury units $(47 \%)$ and two were children's units $(6 \%)$. These 36 units saw a total of 1118451 attendances in the previous year (range 50-126 591), which included 355579 children (range 20-39 403). There was a $100 \%$ response rate to the questionnaire; this was most probably achieved as a result of approaching identified individuals at each unit.

Compliance with the first three recommendations of the Multidisciplinary Working Party by unit type is demonstrated in table 1 . Within both children's A\&E departments there was complete audio-visual separation from adults, paediatric inpatient facilities were available and registered children's nurses were always on duty.

Among the 17 mixed A\&E units complete audio-visual separation from adults was provided in six units $(35 \%)$, paediatric inpatient facilities were available at 11 units $(65 \%)$, and registered children's nurses were always on duty in three units $(18 \%)$. Separate waiting facilities for children were available in 11 units $(65 \%)$ and separate triage facilities in one unit. Computerised records were kept by 16 units $(94 \%)$ and regular paediatric resuscitation training took place in 13 units (76\%). A named $\mathrm{A} \& \mathrm{E}$ doctor was responsible for children's issues in seven units $(41 \%)$ and a named senior nurse in 14 units $(82 \%)$. A doctor with paediatric experience was always on duty in eight units $(47 \%)$.

The 17 minor injury units saw 54237 children in the previous year $(15 \%$ of all children seen in Trent). One unit provided audio-visual separation from adults, paediatric inpatient facilities were not available at any unit, and registered children's nurses were always on duty in one unit. Computerised records were kept in four units $(24 \%)$, a named $\mathrm{A} \& \mathrm{E}$ doctor was responsible for children's issues in one unit and regular paediatric resuscitation training took place in 11 units (65\%).

Some facilities should be available in all units, regardless of size. The Multidisciplinary Working Party recommend that in minor injury units "staff must have the equipment, skills and knowledge to assess and provide resuscitation and stabilization" and "knowledge, skills and expertise in awareness of, and initial management of children with suspected non-accidental injury". Questions on resuscitation facilities revealed that systems for the assessment of the weight of a child were used in 22 units overall $(61 \%)$ and the Broselow system was the most common method. There was a wide range of different drugs stocked in resuscitation rooms; of the 45 drugs suggested in the checklist produced by Phillips ${ }^{5}$ each unit kept a mean of 29 drugs (range 4-44). There was an equally wide range in the equipment carried in the resuscitation room, with a distinct shortage of equipment for the smallest children.

Written guidelines were available for the management of non-accidental injury in 35 units overall (97\%), cot death in 24 units $(67 \%)$, deliberate self harm in 19 units $(53 \%)$, pain relief in 27 units $(75 \%)$ and burns and scalds in 31 units $(86 \%)$. Paediatric pain assessment tools were used in only 21 units overall (58\%).

Other facilities available were a breast feeding area in 18 units overall (50\%), nappy changing facilities in 29 units $(81 \%)$, pushchair storage areas in eight units $(22 \%)$ and health information/accident prevention posters were displayed in all 36 units (100\%). Regarding safety issues, socket covers were used in 18 units overall $(50 \%)$, hot drinks were not allowed in waiting areas in 17 units $(47 \%)$ and high door handles were used in 10 units (28\%). Information sheets were provided on head injury in 36 units (100\%), fever in 17 units (47\%), febrile convulsions in 16 units (44\%) and gastroenteritis in nine units $(25 \%)$.

A quiet room was provided by 26 units overall $(72 \%)$ and contained a pay phone in 16 units (44\%), a mirror in 15 units (42\%), a drinks machine in 13 units (36\%), an engaged sign in 11 units $(31 \%)$ and a sink in 10 units $(28 \%)$.

Play specialists are recommended in units that see more than 18000 children annually; there were five such units within Trent and four of them $(80 \%)$ employed a play specialist. In all units a nominated person regularly checked toys for safety and hygiene.

\section{Discussion}

There are several sources of recommendations and guidelines relating to the care of children in A\&E departments. In 1988 the British Paediatric Association, the British Association of Paediatric Surgeons and the Casualty Surgeons Association issued the "Joint statement on children's attendances at accident and emergency departments". ${ }^{6}$ As part of their quality review of services for children, Action for Sick Children (formerly The National Association for the Welfare of Children in Hospital) produced the NAWCH Checklist for A\&E departments. This and other practical recommendations were incorporated into the recently updated Royal College of Nursing document regarding the provision of nursing services for children in the A\&E department. ${ }^{7}$ Other sources of recommendations include publications by the Department of Health, other professional organisations and health service consumer groups. ${ }^{8-10}$

The Multidisciplinary Working Party into Accident and Emergency Services for Children 
was convened by the Royal College of Paediatrics and Child Health, and the British Association for Accident and Emergency Medicine and included representatives from other relevant bodies. The aims of the group were to review current arrangements for $\mathrm{A} \& \mathrm{E}$ services for children and young children, to make recommendations for the future provision of these services and, to deal with consequent training issues and to consider an intercollegiate advisory structure.

This survey shows that there is a wide variation in the services provided by $\mathrm{A} \& \mathrm{E}$ units within Trent region and that few units currently meet the recommendations of the Multidisciplinary Working Party. In $82 \%$ of the mixed A\&E units in Trent there is an insufficient number of registered sick children's nurses. This problem has been envisaged and the Multidisciplinary Working Party states that Trusts "must develop an effective long-term strategy for the recruitment and retention" of such nurses, and suggests that progress towards this goal should be substantial by 2004 . Furthermore, 63000 children are seen annually at the six mixed A\&E units in Trent that do not offer paediatric inpatient services; this represents $18 \%$ of all children seen within the region. The Multidisciplinary Working Party recognises that co-location with paediatric inpatient services may be difficult for geographically isolated trusts, for whom special arrangements must be made, but specifies that arrangements need to be made for the re-direction of children to appropriately supported units. It is recommended that these facilities, or a clear, timetabled plan for their implementation should be in place by 2004 .
In conclusion, few units within Trent, apart from children's A\&E units, currently meet the key recommendations of the Multidisciplinary Working Party. Further shortcomings, such as the shortage of resuscitation equipment for smaller children, or the lack of use of children's pain assessment tools, are equally of concern. The provision of certain facilities is commendable however, such as play specialists, clinical guidelines and health information.

I am grateful to the following individuals for their help in the design, execution and analysis of this project; Mrs Alison Bond, Dr David Thomas, Miss Lynn Williams and Dr Barbara Phillips.

\section{Contributor}

Please note that I am the sole author and guarantor of this paper.

1 Action for Sick Children. Emergency health services for children and young people. A guide for commissioners and providers. London: Action for Sick Children, 1997.

2 Muller D. Nursing children: psychology, research and practice. London: Chapman and Hall, 1992.

3 Royal College of Paediatrics and Child Health. Accident and emergency services for children. Report of a Multidisciplinary Working Party. London: Royal College of Paediatrics and Child Health, 1999.

Child Health, 1999.
NHS Executive. Trent Directory 1998/99. Manchester: NHS Executive, 1998.

5 Phillips B. Emergency room requirements for children. In: Ward Platt MP, Little RA, eds. Injury in the young. Cambridge: Cambridge University Press 1998.

6 British Paediatric Association, British Association of Paediatric Surgeons, Casualty Surgeons Association. Foint statement on children's attendances at accident and emergency departments. London: British Paediatric Association, 1988

7 Royal College of Nursing. Nursing children in the accident and emergency department. London: Royal College of Nursing 1998.

8 Department of Health. Welfare of children and young people in hospital. London: HMSO, 1991.

9 Health Services Accreditation. Standards for accident and emergency Services, 1997.

10 Department of Health. The patient's charter. Services for children and young people. London: HMSO, 1996.

\section{Referees for Emergency Medicine fournal}

All papers submitted for publication in Emergency Medicine fournal undergo peer review. As a result of the continuing rise in the number of papers received the journal seeks additional referees.

This is an interesting and stimulating activity. The editorial office ensures that the workload for referees is not onerous and guidelines are provided to allow a structured critique of each paper. Referees are expected to return comments within 21 days of receipt of the manuscript.

Please contact the editors, Emergency Medicine fournal at BMA House, Tavistock Square, London WC1H 9JR; tel: 0207383 6795; fax: 0207383 6668; email: kwalsh@bmjgroup.com stating your present appointment and any areas of special expertise. Referees are particularly welcome from other specialties with an interest in emergency medicine and from outside the $\mathrm{UK}$. 